\title{
PENGARUH TURNOVER INTENTION DAN KEPUASAN KERJA TERHADAP PRODUKTIVITAS KERJA SALES PROMOTION GIRL (SPG) MATAHARI DEPARTMENT STORE - BEKASI
}

\author{
Bintang Narpati ${ }^{1}$, Andrian' ${ }^{2}$, M. Fadhli Nursal ${ }^{3}$ \\ Universitas Bhayangkara Jakarta Raya, Bekasi ${ }^{1,2,3}$
}

Email korespondensi: bintang.narpati@dsn.ubharajaya.ac.id ${ }^{1}$

Received: 31 May 2020 Reviewed: 26 June 2020 Accepted: 2 Oct 2020 Published:30 Oct 2020

\begin{abstract}
The purpose of this research was to measure the implications of sales promotion girl (SPG) turnover intention on work productivity at Matahari Department Store Metropolitan Mall Bekasi. The method used in this research is to use a quantitative descriptive analysis involving Sales Promotion Girl (SPG) of PT Matahari Department of Metropolitan Mall Bekasi Store using non-probability sampling techniques of 300 (three hundred) people. The data analysis technique used is a multiple linear regression analysis technique using the Statistical Package for the Social Sciences version 24. The results showed that there was a significant influence both partially and simultaneously from the independent variable on the dependent variable. Turnover has a positive effect on work productivity as well as job satisfaction. Simultaneously the independent variable has a positive effect with a value of $77.0 \%$ while $23.0 \%$ is influenced by other factors.
\end{abstract}

Keywords: Turnover, Job Satisfaction, Work Productivity

\begin{abstract}
ABSTRAK
Tujuan penelitian ini adalah mengukur implikasi turnover intention sales promotion girl (SPG) terhadap produktvitas kerja di Matahari Department Store Metropolitan Mall Bekasi. Metode yang digunakan dalam penelitian ini adalah analisa deskriptif kuantitatif yang melibatkan Sales Promotion Girl (SPG) Matahari Departemen Store Metropolitan Mall Bekasi sebagai sampel. Sampel didapatkan dengan teknik non probablitiy sampling sebanyak 300 (tiga ratus) orang. Teknik analisis data yang digunakan adalah teknik analisis regresi linier ganda dengan mengggunakan Statistic Package for the Social Sciences version.24. Hasil penelitian didapat bahwa ada secara signifikan baik secara parsial maupun secara simultan dari variabel bebas terhadap variabel terikat. Turnover berpengaruh positif terhadap produktivitas kerja begitu pula dengan Kepuasan Kerja. Secara simultan variabel bebas berpengaruh positif dengan nilai 77,0\% sedangkan 23,0\% dipengaruhi oleh faktor lainnya.
\end{abstract}

Kata kunci: Turnover, Kepuasan Kerja, Produktivitas Kerja.

\section{A. PENDAHULUAN}

Matahari Department Store adalah perusahaan ritel di Indonesia yang menyajikan berbagai macam pakaian, baik anak - anak hingga dewasa. Perusahaan ini merupakan salah 
satu anak perusahaan dari Lippo Group. Menurut manajer personalia Matahari Department Store Metropolitan Mall Bekasi, beberapa permasalahan yang dihadapi yaitu keluar masuknya (turnover) karyawan apabila tidak mencapai target yang telah ditetapkan oleh perusahaan. Selain turnover intention, variabel lain yang mempengaruhi produktivitas kerja karyawan di perusahaan ini adalah kepuasan kerja yang dirasakan oleh karyawan. Dengan adanya turnover intention dan kepuasan kerja akan mempengaruhi kepada produktivitas kerja karyawan di PT Matahari Department Store Bekasi.

Menurut Mathis \& Jackson (2004), turnover intention merupakan keadaan dari seorang karyawan yang secara sadar untuk mencari pekerjaan lain dengan melakukan perpindahan dari satu organisasi ke organisasi lain. Turnover intention yang dilakukan oleh seorang karyawan ada yang dilakukan secara sukarela maupun tidak. Turnover intention tidak sukarela adalah turnover yang dilakukan oleh karyawan karena karyawan tersebut memiliki kinerja yang buruk dan telah melakukan pelanggaran atau dikeluarkan oleh perusahaan. Dikeluarkannya karyawan ini akibat dari karyawan tersebut tidak dapat mengikuti kebijakan organisasi, peraturan kerja, dan standar kerja yang ditetapkan oleh perusahaan. Sedangkan turnover intention sukarela adalah keluarnya karyawan dari suatu organisasi atas keinginannya sendiri.

Menurut penelitian yang dilakukan oleh Wahyuni, dkk (2014) pada perusahaan jasa konstruksi faktor internal yang memiliki persentase terbesar dalam mempengaruhi turnover karyawan adalah komitmen. Komitmen yang telah tertanam pada diri seorang karyawan untuk berpindah perusahaan merupakan kekuatan yang besar. Faktor internal lainnya adalah hubungan kerja dengan pimpinan atau atasan. Adanya hubungan kerja dengan atasan yang tidak baik akan mengakibatkan seorang karyawan akan melakukan perpindahan perusahaan ke tempat lain. Sedangkan faktor eksternal yang mempengaruhi turnover adalah gaji dan insentif. Persentase gaji memiliki persentase yang lebih besar dibandingkan dengan insentif yang diterima.

Baruch-Feldman, dkk (2002) mengemukakan bahwa dukungan atasan langsung berkorelasi positif dengan kepuasan kerja karena dengan kepuasan kerja akan menghasilkan produktivitas yang tinggi. Dukungan atasan langsung memberikan suatu motivasi yang diperlukan bagi karyawan. Karyawan yang mencintai pekerjaannya dan dengan segala pengorbanan baik waktu dan keadaan kondisi fisiknya tetap memikirkan pekerjaannya, dapat dikategorikan bahwa karyawan tersebut memiliki kepuasan kerja terhadap pekerjaan yang 
dijalankannya saat itu (P. S. Robbins, 2002). Melalui kecintaan terhadap pekerjaannya, karyawan akan berusaha menghasilkan hasil yang terbaik bagi perusahaan dan kepuasan kerja bagi dirinya sendiri.

Penelitian ini menggunakan variabel turnover intenion dan kepuasan kerja untuk mengukur keterkaitan dengan variabel terikat yaitu produktivitas kerja karyawan. Penelitian terhadap variabel - variabel tersebut oleh Aprilianasari (2017) menemukan bahwa turnover intention memiliki pengaruh yang signifikan terhadap produktivitas kerja karyawan di PT Matahari Department Store Tbk Cabang Kediri. Penelitian yang dilakukan oleh Rompis \& Sendow (2019) terhadap perusahaan CV Segarindo Utama menemukan bahwa secara parsial insentif, turnover intention dan keterlibatan kerja berpengaruh secara signifikan terhadap produktivitas kerja. Penelitian yang dilakukan oleh Hendri \& Rismansyah (2016) menyatakan bahwa ada pengaruh kepuasan kerja terhadap produktivitas kerja karyawan pada PT Selapan Jaya OKI.

Penelitian yang dilakukan oleh Fu'ad \& Gumilar (2018) terhadap karyawan CV Duta Jepara, menyatakan bahwa turnover intention berpengaruh terhadap keunggulan bersaing, tetapi tidak berpengaruh terhadap produktivitas. Penelitian yang dilakukan oleh Muayyad \& Gawi (2016) terhadap karyawan Bank Syariah X Kanwil II menunjukkan hasil bahwa kepuasan kerja secara signifikan tidak berpengaruh terhadap produktivitas kerja karyawan. Dari hasil penelitian di atas dapat disimpulkan bahwa adanya inkonsistensi hasil penelitian antara turnover intention dan kepuasan kerja terhadap produktivitas kerja.

\section{B. TELAAH PUSTAKA}

\section{Turnover Intention}

Turnover intention merupakan interaksi karyawan terhadap organisasinya. Turnover intention adalah niat karyawan untuk keluar dari perusahaan, walaupun demikian sebagian perusahaan berusaha mempertahankan karyawan yang berharga dan meningkatkan efektivitas organisasi Hom, dkk (2012). Turnover intention adalah keinginan untuk keluar dari perusahaan bagi seorang karyawan (Zaffane, 2003). Pendapat Allen \& Griffeth (2001) mengatakan bahwa turnover atau pindah kerja merupakan pegawai yang berhenti dari suatu organisasi/perusahaan dan pindah kerja ke organisasi/perusahaan lain dengan alasan tertentu oleh masing - masing karyawan. Turnover intention sendiri antara lain dipengaruhi oleh iklim etis di tempat kerja, kepuasan kerja karyawan, dan komitmen organisasi dari karyawan 
(Schwepker, 2001). Menurut Egan, dkk (2004) turnover intention dapat menjadi negatif karena adanya budaya organizational learning dan kepuasan kerja yang menjadikan karyawan merasakan adanya lingkungan yang nyaman dalam bekerja.

Dari beberapa pendapat tersebut dapat disimpulkan bahwa turnover intention karyawan adalah kecenderungan sikap atau tingkat dimana seorang karyawan memiliki kemungkinan untuk meninggalkan organisasi atau mengundurkan diri secara sukarela dari pekerjaannya. Hal ini disebabkan karena adanya beberapa faktor diantaranya adanya ketidakpuasan dalam bekerja, tidak adanya komitmen organisasi dan iklim kerja yang tidak kondusif. Turnover intention karyawan ini ada di setiap sektor industri bisnis, mulai dari perbankan, industri migas, sektor manufaktur, department store, dan sebagainya. Ada tiga indikator turnover intention karyawan, yaitu : 1) Pikiran untuk berhenti bekerja (thoughts of quitting). Adanya pikiran berhenti bekerja karena karyawan merasa tidak puas dengan keadaan pekerjaan yang sekarang, sehingga memicu untuk berkurangnya kehadiran dalam bekerja. 2) Hasrat untuk meninggalkan karir (intention to quit). Mencerminkan individu untuk mencari pekerjaan pada organisasi lain. Jika karyawan sudah mulai sering berfikir untuk keluar dari pekerjaannya, karyawan tersebut akan mencoba mencari pekerjaan di luar perusahaannya yang dirasa lebih baik. 3) Hasrat untuk mencari pekerjaan lain (intention to search for another job). Adanya kecenderungan karyawan keluar dari perusahaan karena mendapatkan tawaran pekerjaan di luar yang menurutnya lebih menarik dibandingkan dengan tempat bekerjanya sekarang. (Mobley, 2011).

\section{Kepuasan Kerja}

Karyawan yang memiliki komitmen terhadap organisasi cenderung memiliki kepuasan kerja (Saari \& Judge, 2004), sehingga menimbulkan motivasi yang besar untuk terus memperbaiki kinerjanya. Selain itu, nilai kerja dan imbalan merupakan faktor yang mempengaruhi kepuasan kerja (Kalleberg, 2006). Dikarenakan kedua faktor tersebut menjadikan karyawan melakukan pekerjaannya dengan sebaik - baiknya. Menurut penelitian Yasa (2017) kepuasan kerja berpengaruh negatif terhadap turnover intention. Dari beberapa pendapat di atas, dapat disimpulkan bahwa kepuasan kerja adalah keadaan psikis menyenangkan yang dirasakan oleh pekerja dalam suatu lingkungan pekerjaan karena terpenuhinya kebutuhan secara memadai.

Kepuasan kerja karyawan biasanya dipengaruhi oleh beberapa faktor, antara lain pekerjaan yang dianggap menantang bagi karyawan, penghargaan, kondisi lingkungan kerja 
dan hubungan interpersonal. (S. Robbins \& Judge, 2013). Pekerjaan yang dianggap kurang menantang dapat menciptakan kebosanan bagi karyawan itu sendiri. Namun, apabila pekerjaan yang terlalu menantang, juga akan menciptakan keadaan frustasi bagi pegawai perilaku dan perasaan gagal. Penghargaan diterima sesuai dengan harapan karyawan. Kondisi kerja yang mendukung, seperti tata ruang, kebersihan ruang kerja, fasilitas dan alat bantu, temperatur, dan tingkat kebisingan. Sedangkan, hubungan interpersonal terkait dengan kolega yang saling mendukung atas pekerjaan. Selain itu, perilaku atasan dapat menjadi faktor penentu kepuasan karyawan yang paling utama.

Indikator kepuasan kerja menurut S. Robbins \& Judge (2013) adalah menyenangi pekerjaannya, mencintai pekerjaannya, imbalan kerja, dan prestasi kerja. Dari penjelasan tersebut bahwa kepuasan kerja dapat terwujud jika baik pengurus maupun karyawan bekerja sama dan saling mendukung dengan baik sehingga tujuan dapat terwujud sesuai dengan kesepakatan. Hal ini ditunjukkan pada sikap kerja masing-masing karyawan.

\section{Produktivitas Kerja}

Produktivitas kerja adalah perbandingan antara output (hasil) dengan input (masukan) (Hasibuan, 2012). Produktivitas kerja dapat naik jika ada peningkatan efisiensi (waktu-bahantenaga) dan juga ada sistem kerja yang dibuat oleh perusahaan. Selain itu juga adanya peningkatan teknik produksi dan keterampilan dari tenaga kerjanya. Produktivitas kerja dapat dihasilkan melalui pelatihan kerja sehingga menghasilkan kinerja yang tinggi (Huselid, 2018). Produktivitas kerja memiliki hubungan yang searah dengan kepuasan kerja menurut penelitian Febrianto, dkk (2016).

Dapat disimpulkan dari pengertian di atas bahwa produktivitas kerja adalah pelaksanaan pekerjaan dari karyawan yang memproduksi dibandingkan dengan input yang digunakan dalam produksi. Seorang karyawan dapat dikatakan produktif apabila mampu menghasilkan barang atau jasa sesuai harapan dalam waktu yang singkat atau tepat. Pengukuran produktivitas kerja pada suatu perusahaan menunjukkan adanya perubahan pada tingkat tertentu. Melalui pengukuran produktivitas kerja pihak manajemen dapat mengetahui bahwa usahanya sedang berkembang. Pengukuran produktivitas kerja dilakukan dengan mengukur perubahan produktivitas kerja sehingga dapat dilakukan penilaian terhadap usaha untuk memperbaiki produktivitas. Pengukuran produktivitas kerja dapat bersifat prospektif dan berfungsi sebagai masukan untuk pengambilan keputusan strategis. Jenis-jenis produktivitas kerja terbagi dua yaitu produktivitas kerja total dan produktivitas kerja parsial. 
Ada beberapa faktor yang mempengaruhi produktivitas, antara lain bersumber dari pekerjaan, bersumber dari karyawan itu sendiri, gaji yang memadai, kebutuhan karyawan perlu diperhatikan, penempatan karyawan pada posisi yang tepat, pendidikan, kesehatan jasmani dan rohani, lingkungan kerja, faktor manajerial, motivasi, peralatan yang digunakan. Beberapa faktor yang dapat digunakan untuk pengukuran ukuran produktivitas kerja dapat ditentukan oleh sasaran atau tujuan tindakan harus objektif, fasilitas atau ketersediaan bagi pekerja, perbandingan antara pekerja dengan waktu dan kualitas serta pengendalian yaitu fokus pada hasil. (Sauermann, 2016).

\section{Penelitian Sebelumnya}

\section{Pengaruh Turnover Intention terhadap Produktivitas Kerja}

Perpindahan kerja yang dilakukan oleh karyawan dari satu perusahaan ke perusahaan lainnya memberikan dampak kepada produktivitas kerja. Turnover intention ini dilakukan baik secara sukarela maupun karena faktor lingkungan kerja dan beban kerja. Karyawan tetap menunjukkan produktivitas kerja walaupun ingin meninggalkan perusahaan sebelumnya. Penelitian ini diperkuat dengan penelitian sebelumnya oleh Aprilianasari (2017) yang menyatakan bahwa adanya pengaruh positif dan signifikan antara turnover intention terhadap produktivitas kerja.

Menurut Rini Aprilianasari (2017) yang telah melakukan penelitian pada bagian kasir PT Matahari Department Store Kediri menyatakan bahwa secara parsial turnover intention berpengaruh signifikan terhadap produktivitas kerja karyawan di PT Matahari Department Store Tbk Cabang Kediri dan secara simultan variabel disiplin kerja, prestasi kerja, dan turnover secara simultan berpengaruh signifikan terhadap variabel dependen yaitu produktivitas kerja karyawan di PT Matahari Department Store Tbk Cabang Kediri. Menurut penelitian sebelumnya yaitu Asmara (2017) yang meneliti di RS Bedah Surabaya menyatakan bahwa turnover intention berpengaruh terhadap kinerja karyawan.

\section{Pengaruh Kepuasan Kerja terhadap Produktivitas Kerja}

Hubungan personal baik sesama karyawan dan antara atasan dengan bawahan dapat menjadikan kepuasan kerja bagi karyawan sebagai motivasi kerja walaupun adanya target atau beban kerja yang diberikan kepada karyawan. Penelitian ini diperkuat dari penelitian sebelumnya yaitu Said, dkk (2017) yang melakukan penelitian pada PT Bank Mandiri (Persero) Tbk Area Manado. Hasil penelitian menunjukkan bahwa variabel kepuasan kerja berpengaruh signifikan terhadap produktivitas kerja. Hoboubi et al (2017) melakukan 
penelitian terhadap karyawan dari perusahaan Irianian Petrochemical yang menunjukkan bahwa adanya pengaruh positif signifikan antara kepuasan kerja terhadap produktivitas kerja.

Adapun hipotesis yang digunakan dalam penelitian ini adalah:

$\mathrm{H}_{1}$ : Terdapat pengaruh antara turnover intention $\left(\mathrm{X}_{1}\right)$ secara signifikan terhadap produktivitas kerja (Y)

$\mathrm{H}_{2}$ : Terdapat pengaruh secara signifikan antara kepuasan kerja $\left(\mathrm{X}_{2}\right)$ terhadap produktivitas kerja (Y)

$\mathrm{H}_{3}$ : Terdapat pengaruh secara signifikan antara turnover intention $\left(\mathrm{X}_{1}\right)$ dan kepuasan kerja $\left(\mathrm{X}_{2}\right)$ secara simultan terhadap produktivitas kerja $(\mathrm{Y})$

Gambar 1. Kerangka Berpikir

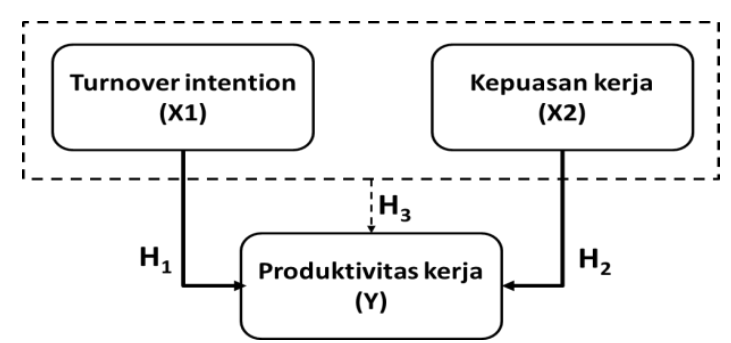

$\longrightarrow$ : Pengaruh variabel $\mathrm{X}_{1}$ dan $\mathrm{X}_{2}$ terhadap $\mathrm{Y}$ secara parsial

$---\rightarrow$ : Pengaruh variabel $\mathrm{X}_{1}$ dan $\mathrm{X}_{2}$ terhadap $\mathrm{Y}$ secara simultan

\section{METODOLOGI PENELITIAN}

Desain penelitian ini menggunakan penelitian deskriptif kuantitatif. Proses penelitian ini berupa pengumpulan data yang didapat dari penyebaran kuesioner terhadap karyawan Matahari Department Store Metropolitan Mall Bekasi. Dalam penelitian ini menggunakan teknik random sampling dengan jumlah responden sebesar 300 karyawan. Penyusunan data, pengolahan data menggunakan SPSS 24 dan serta analisis data yang nantinya dapat dijadikan kesimpulan oleh peneliti. Data primer yang digunakan berupa data dari wawancara mendalam dengan kepala unit kerja Matahari Department Store Metropolitan Mall Bekasi.

\section{HASIL DAN PEMBAHASAN}

\section{Hasil Uji Statisik}

Uji validitas digunakan pada tiap butir soal dengan analisis item, yaitu mengolerasikan atau menghubungkan skor masing - masing butir dibandingkan dengan skor total yang merupakan jumlah skor tiap butir (Sugiyono, 2013). Kuesioner dikatakan valid apabila r- 
hitung > r-tabel. Pada penelitian ini, r-tabel =0,1133 dengan taraf signifikansi 5\% dan sample $(\mathrm{N}=300)$.

Tabel 1. Uji Validitas

\begin{tabular}{|c|c|c|c|c|c|}
\hline \multirow[b]{2}{*}{ Pertanyaan } & \multicolumn{3}{|c|}{ R - Hitung } & \multirow[b]{2}{*}{$\begin{array}{c}\text { R-Tabel } \\
(5 \%, N=300)\end{array}$} & \multirow[b]{2}{*}{ Keterangan } \\
\hline & $\begin{array}{l}\text { Turnover } \\
\text { (X1) }\end{array}$ & $\begin{array}{l}\text { Kepuasan } \\
\text { Kerja (X2) }\end{array}$ & $\begin{array}{c}\text { Produktivitas } \\
\text { Kerja (Y) }\end{array}$ & & \\
\hline 1 & 0.529 & 0.646 & 0.733 & 0.1133 & valid \\
\hline 2 & 0.587 & 0.676 & 0.734 & 0.1133 & valid \\
\hline 3 & 0.580 & 0.681 & 0.746 & 0.1133 & valid \\
\hline 4 & 0.624 & 0.689 & 0.747 & 0.1133 & valid \\
\hline 5 & 0.624 & 0.698 & 0.606 & 0.1133 & valid \\
\hline 6 & 0.569 & 0.743 & 0.778 & 0.1133 & valid \\
\hline 7 & 0.559 & 0.718 & 0.798 & 0.1133 & valid \\
\hline 8 & 0.542 & 0.700 & 0.732 & 0.1133 & valid \\
\hline 9 & 0.555 & 0.733 & 0.779 & 0.1133 & valid \\
\hline 10 & 0.527 & 0.715 & 0.601 & 0.1133 & valid \\
\hline
\end{tabular}

Sumber: Data primer diolah (2020)

Uji reliabilitas mengukur suatu indeks apakah dapat dipercaya atau dapat diandalkan. Mengetahui tingkat reliabilitas dapat dilakukan pengujian pada masing-masing data dari variabel terkait. Variabel dapat dikatakan reliabel jika variabel tersebut memberikan nilai cronbach alpha > 0,7 (Ghozali, 2011). Hasil penelitian menunjukkan cronbach's alpha lebih besar dari 0,7 sehingga penelitian dikatakan reliable.

Tabel 2. Uji Reliabilitas

\begin{tabular}{|c|c|c|}
\hline Variabel & Cronbach's Alpha & N of Items \\
\hline $\mathrm{X}_{1}$ & 0.746 & 7 \\
\hline $\mathrm{X}_{2}$ & 0.875 & 9 \\
\hline $\mathrm{Y}$ & 0.899 & 10 \\
\hline
\end{tabular}

Sumber: Data primer diolah (2020)

Uji normalitas menunjukkan adanya sebaran data yang seimbang sebagian besar data berada pada nilai di tengah. Pada prinsipnya normalitas dapat dideteksi dengan melihat penyebaran data (titik). Titik - titik tersebut mengikuti garis sumbu diagonal dari grafik atau dapat dilihat dari histogram dari residualnya (Ghozali, 2011). Pada penelitian ini terlihat titik 
- titik menyebar membentuk diagonal, sehingga variabel - variabel dikatakan normal. Pada uji kolmogorov - smirnov dihasilkan siginifikansi sebesar 0,200 atau lebih besar dari 0,05.

Tabel 3. Uji Normalitas - One Sample K-S Test

Sumber: Data primer diolah (2020)

\begin{tabular}{|l|c|}
\hline & Unstandardized Residual \\
\hline $\mathrm{N}$ & 300 \\
\cline { 1 - 1 } Test Statistic & 0.200 \\
\hline
\end{tabular}

Uji multikolinieritas adalah pengujian untuk mengetahui ada tidaknya kolerasi yang sgnifikan antar variabel-variabel independen dalam model regresi linier berganda. Untuk mendeteksi ada tidaknya multikolinieritas dalam model regresi dapat digunakan VIF dan lawannya tolerance. Nilai cutoff yang biasa dipakai untuk menunjukkan adanya Multikolinieritas adalah nilai tolerance $\geq 0,10$ atau sama dengan VIF $\leq 10$ (Ghozali, 2011).

Dari output coefficients di bawah ini, pada kolom VIF nilainya 2,212. Karena nilai VIF kurang dari 10 maka dapat disimpulkan bahwa pada model regresi tidak ditemukan adanya masalah multikolinieritas.

Tabel 4. Uji Multikolinieritas

\begin{tabular}{|ll|r|r|r|}
\hline Model & & $\begin{array}{r}\text { Unstandardized } \\
\text { B }\end{array}$ & $\begin{array}{c}\text { Collinearity } \\
\text { Tolerance }\end{array}$ & $\begin{array}{c}\text { Statistics } \\
\text { VIF }\end{array}$ \\
\hline 1 & (Contstant) & 1.884 & & \\
& Turnover & 0.73 & 0.452 & 2.212 \\
& Kepuasan Kerja & 0.656 & 0.452 & 2.212 \\
\hline
\end{tabular}

Sumber: Data primer diolah (2020)

Uji heteroskedastisitas menguji tentang penyimpangan yaitu adanya ketidaksamaan varian dan residual untuk semua pengamatan pada model regresi dalam hal ini regresi berganda. Model regresi yang baik adalah yang homoskedastisitas atau tidak terjadi heteroskedastisitas (Ghozali, 2011).

Output correlations pada tabel 5, dapat diketahui korelasi antara turnover dengan unstandardized residual menghasilkan nilai signifikansi 0,663 dan korelasi antara kepuasan kerja menghasilkan nilai signifikansi 0,055. Karena nilai signifikansi korelasi lebih besar dari 0,05 maka dapat disimpulkan bahwa pada model regresi tidak ditemukan adanya masalah 
heteroskedastisitas. Persamaan regresi hasil dari penelitian ini dapat dirumuskan sebagai berikut : $\mathrm{Y}=1,884+0,730 \mathrm{X}_{1}+0,656 \mathrm{X}_{2}$

Tabel 5. Uji Heteroskedastisitas

\begin{tabular}{|c|c|c|c|c|c|}
\hline \multirow{4}{*}{$\begin{array}{l}\text { Spearman's } \\
\text { rho }\end{array}$} & & & $\begin{array}{c}\text { Unstandardized } \\
\text { Residual }\end{array}$ & Turnover & $\begin{array}{c}\text { Kepuasan } \\
\text { Kerja }\end{array}$ \\
\hline & $\begin{array}{l}\text { Unstandardized } \\
\text { Residual }\end{array}$ & $\begin{array}{l}\text { Correlation } \\
\text { Coefficient } \\
\text { Sig. (2-tailed) } \\
\mathrm{N}\end{array}$ & $\begin{array}{l}1.000 \\
0.300 \\
\end{array}$ & $\begin{array}{l}0.025 \\
0.663 \\
0.300 \\
\end{array}$ & $\begin{array}{r}-0.111 \\
0.055 \\
0.300 \\
\end{array}$ \\
\hline & Turnover & $\begin{array}{l}\text { Correlation } \\
\text { Coefficient } \\
\text { Sig. (2-tailed) } \\
\text { N }\end{array}$ & $\begin{array}{r}-0.025 \\
0.663 \\
0.300\end{array}$ & $\begin{array}{l}1.000 \\
0.300\end{array}$ & $\begin{array}{l}0.744 \\
0.000 \\
0.300\end{array}$ \\
\hline & Kepuasan Kerja & $\begin{array}{l}\text { Correlation } \\
\text { Coefficient } \\
\text { Sig. (2-tailed) } \\
\mathrm{N}\end{array}$ & $\begin{array}{r}-0.111 \\
0.055 \\
0.300\end{array}$ & $\begin{array}{r}0.744 \\
0 \\
0.300\end{array}$ & 1.000 \\
\hline
\end{tabular}

Sumber: Data primer diolah (2020)

Pada dasarnya uji-t menunjukkan seberapa jauh pengaruh satu variabel penjelas secara individual dalam menerangkan variasi variabel penjelas secara individual dalam menerangkan variasi variabel terikat (Kuncoro, 2010).

Tabel 6. Uji Parsial (t-test)

\begin{tabular}{|ll|r|r|l|}
\hline Model & & Unstandardized B & t & sig \\
\hline 1 & (Contstant) & 1.884 & 1.005 & 0.316 \\
& Turnover & 0.73 & 7.962 & 0.000 \\
& Kepuasan Kerja & 0.656 & 14.626 & 0.000 \\
\hline
\end{tabular}

Sumber: Data primer diolah (2020)

Dari tabel 6, diketahui bahwa turnover intention $\left(\mathrm{X}_{1}\right)$ memiliki nilai sig. $0,00<0,05(\alpha$ sig) dan t-hit 7,962 > t-tabel 1,968 dapat diartikan bahwa adanya pengaruh yang signifikan antara variabel bebas turnover $\left(\mathrm{X}_{1}\right)$ terhadap variabel terikat produktivitas kerja $(\mathrm{Y})$. Kepuasan kerja $\left(\mathrm{X}_{2}\right)$ memiliki nilai sig. 0,00<0,05( $\alpha$ sig) dan t-hit 14,626 > t-tabel 1,968 dapat diartikan bahwa adanya pengaruh yang signifikan antara variabel bebas kepuasan kerja $\left(\mathrm{X}_{2}\right)$ terhadap variabel terikat produktivitas kerja $(\mathrm{Y})$. 
Pada dasarnya uji f menunjukkan apakah semua variabel bebas yang dimasukkan dalam model mempunyai pengaruh secara bersama-sama terhadap variabel terikat (Kuncoro, 2010).

Tabel 7. Uji F

ANOVA

\begin{tabular}{|cc|c|c|c|}
\hline Model & & df & F & sig \\
\hline 1 & Regression & 2 & 497.360 & 0.000 \\
& Residual & 297 & & \\
& Total & 299 & & \\
\hline
\end{tabular}

Sumber: Data primer diolah (2020)

Pada uji F ini, didapat nilai $\mathrm{F}_{\text {-hit }}>$ dari $\mathrm{F}_{\text {-tabel }}$ dimana nilainya 497,360 > 3,026, sehingga dapat disimpulkan bahwa secara simultan variabel bebas yaitu turnover $\left(\mathrm{X}_{1}\right)$ dan kepuasan kerja $\left(\mathrm{X}_{2}\right)$ memiliki pengaruh secara signifikan terhadap variabel terikat yaitu produktivitas $\operatorname{kerja}(\mathrm{Y})$.

Koefisien determinasi $\left(\mathrm{R}^{2}\right)$ pada intinya mengukur seberapa jauh kemampuan model dalam menerangkan variasi variabel terikat (Kuncoro, 2010). Pada hasil koefisien determinasi $\left(\mathrm{R}^{2}\right)$ dihasilkan nilai 0,77 atau $77,0 \%$ yang berarti bahwa pengaruh variabel bebas $\mathrm{X}_{1}$ dan $\mathrm{X}_{2}$ terhadap variabel terikat Y memiliki nilai sebesar 77,0\%, sedangkan sisanya 23,0\% variabel yang tidak diteliti dalam penelitian ini.

Tabel 8. Koefisien Determinasi

\begin{tabular}{|c|c|r|r|c|}
\hline Model & R & R Square & $\begin{array}{c}\text { Adjusted R } \\
\text { Square }\end{array}$ & $\begin{array}{c}\text { Std. Error the } \\
\text { Eestimate }\end{array}$ \\
\hline 1 & 0.878 & 0.77 & 0.769 & 4.470 \\
\hline
\end{tabular}

Sumber: Data primer diolah (2020)

Berdasarkan hasil analisis data yang telah dilakukan di atas, hasil penelitian menunjukkan bahwa ada pengaruh yang signifikan antara turnover $\left(\mathrm{X}_{1}\right)$ terhadap produktivitas kerja karyawan (Y).

Berdasarkan hasil pengujian analisis data yang telah dilakukan, didapatkan regresi linier berganda yaitu $\mathrm{Y}=1,884+0,730 \mathrm{X}_{1}+0,656 \mathrm{X}_{2}$. Kemudian dari persamaan tersebut dapat diketahui bahwa perubahan yang terjadi pada variabel terikat searah dengan perubahan yang terjadi pada variabel bebas, hal ini disebabkan oleh koefisien $\mathrm{X}_{1}$ dan $\mathrm{X}_{2}$ yang positif. 


\section{Pembahasan}

\section{Pengaruh Turnover Intention Terhadap Produktivitas Kerja Karyawan PT Matahari Department Store Bekasi}

Hasil penelitian ini menunjukkan bahwa terdapat pengaruh secara positif dan signifikan antara turnover intention terhadap produktivitas kerja karyawan PT Matahari Department Store Bekasi. Hal ini ditunjukkan dari hasil $\mathrm{T}_{\text {-hitung }}>\mathrm{T}_{\text {-tabel }}$ yaitu $(7,962>1,968)$ dengan nilai signifikansi 0,000 < 0,05 yang artinya Ho ditolak dan Ha diterima. Hal ini menunjukkan bahwa turnover intention memiliki pengaruh yang signifikan terhadap produktivitas kerja. Dalam penelitian ini, salah satu indikator turnover intention adalah pikiran untuk berhenti bekerja (thoughts of quitting). Adanya pikiran berhenti bekerja karena karyawan merasa tidak puas dengan keadaan pekerjaan yang sekarang. Untuk itu, diperlukan perhatian pada jam perpindahan kerja karyawan (shift), kondisi karyawan (burnout), dan penyesuaian target atau beban kerja. Pada penelitian ini dapat disimpulkan apabila turnover intention naik, maka akan berpengaruh terhadap produktivitas kerja karyawan. Penelitian ini diperkuat dengan penelitian sebelumnya yang dilakukan oleh Aprilianasari (2017), yang menyatakan bahwa turnover intention berpengaruh positif dan signifikan terhadap produktivitas kerja.

\section{Pengaruh Kepuasan Kerja terhadap Produktivitas Kerja Karyawan PT Matahari Department Store Bekasi}

Hasil penelitian menunjukkan bahwa kepuasan kerja berpengaruh positif dan signifikan terhadap produktivitas kerja karyawan PT Matahari Department Store Bekasi. Hal ini ditunjukkan dengan hasil t-hitung $>\mathrm{t}$-tabel $(14,626>1,968)$ dengan nilai signifikansi $0,000<0,05$ yang artinya Ho ditolak, Ha diterima. Hal ini menunjukkan bahwa kepuasan kerja berpengaruh positif dan signifikan terhadap produktivitas kerja. Salah satu indikator kepuasan kerja adalah menyenangi pekerjaannya, karena dengan mencintai pekerjaannya, karyawan akan bekerja dengan nyaman. Pada penelitian ini dapat disimpulkan bahwa apabila terjadi kenaikan kepuasan kerja maka akan terjadi kenaikan produktivitas kerja. Penelitian ini diperkuat oleh penelitian sebelumnya yang dilakukan oleh Said et al (2017) dan Hoboubi et al (2017) yang menyatakan bahwa kepuasan kerja berpengaruh positif dan signifikan terhadap produktivitas kerja. 


\section{E. KESIMPULAN}

\section{Kesimpulan}

Dari hasil analisa dan pembahasan, maka dapat diperoleh kesimpulan beberapa hal. Pertama, turnover intention secara signifikan berpengaruh positif terhadap produktivitas kerja di PT Matahari Department Store Bekasi. Apabila terjadi peningkatan turnover intention maka akan berpengaruh positif terhadap produktivitas kerja. Kedua, kepuasan kerja secara signifikan berpengaruh positif terhadap produktivitas kerja di PT Matahari Department Store Bekasi. Apabila terjadi peningkatan kepuasan Kerja maka akan terjadi peningkatan terhadap produktivitas kerja. Ketiga, secara bersamaan variabel turnover intention dan kepuasan kerja di PT Matahari Department Store Bekasi berpengaruh secara signifikan terhadap produktivitas kerja dengan nilai $\mathrm{F}_{\text {-hitung }}>\mathrm{F}_{\text {-tabel. }}$

\section{Saran}

Berdasarkan dari hasil penelitian ini, maka saran yang dapat diajukan adalah bagi perusahaan, untuk menghindari adanya turnover intention bagi karyawan, hendaknya dapat memberikan perhatian pada jam perpindahan kerja karyawan (shift), kondisi karyawan (burnout), dan penyesuaian target atau beban kerja dilihat dari kondisi ekonomi saat ini. Selain itu, bagi peneliti selanjutnya, dapat dilakukan dengan variabel beban kerja, stress kerja, dan lingkungan kerja.

\section{DAFTAR PUSTAKA}

Allen, D. G., \& Griffeth, R. W. (2001). Test of Mediated Performance-Turnover Relationship Highlighting the Moderating of Visibility and Reward Contingency. Journal of Applied Psychology, 1014-1021, 86.

Aprilianasari, R. (2017). Pengaruh Turn Over Dispilin Kerja dan Prestasi Kerja Terhadap Produktivitas Karyawan Bagian Kasir di PT. Matahari Department Store Kediri. SimkiEconomic, 1-12. Retrieved from http://simki.unpkediri.ac.id/detail/12.1.02.02.0532

Asmara, A.P. (2017). Pengaruh Turnover Intention Terhadap Kinerja Karyawan Di Rumah Sakit Bedah Surabaya. Jurnal Administrasi Kesehatan Indonesia, 5(2), 123-129.

Baruch-Feldman, C., Brondolo, E., Ben-Dayan, D., \& Schwartz, J. (2002). Sources of social support and burnout, job satisfaction, and productivity. Journal of Occupational Health Psychology, 7(1), 84-93. https://doi.org/10.1037/1076-8998.7.1.84

Egan, T. M., Yang, B., \& Bartlett, K. R. (2004). The effects of organizational learning culture and job satisfaction on motivation to transfer learning and turnover intention. Human Resource Development Quarterly, 15(3), 279-301 https://doi.org/10.1002/hrdq.1104

Febrianto, A., Minarsih, A. M. M. M., \& Warso, M. M. (2016). Pengaruh Insentif, Komunikasi dan Lingkungan Kerja Terhadap Kepuasan Kerja dan Implikasinya 
Terhadap Produktivitas Kerja Di CV. Duta Karya Semarang. Journal of Management 2(2).

Fu'ad, E. N., \& Gumilar, A. G. (2018). Studi empiris pengaruh kepuasan kerja, turnover intention, produktivitas, dan keunggulan bersaing. Jurnal Ekonomi Dan Bisnis, 21(2), 175-202. https://doi.org/10.24914/jeb.v21i2.1821

Ghozali, I. (2011). Aplikasi Analisi Multivariate Dengan Program SPSS 19. Edisi Kelima Semarang : Bandan Penerbitan Universitas Diponegoro.

Hendri, E., \& Rismansyah. (2016). Pengaruh Kepuasan Kerja Dan Semangat Kerja Terhadap Produktivitas Kerja Karyawan Pada Pt. Selapan Jaya Ogan Komering Ilir. Jurnal Wahana Ekonomika, 13(1), 1-15.

Hoboubi N, Choobineh A, Kamari G.F, Keshavarzi S, Akbar H.A. (2017). The Impact of Job Stress and Job Satisfaction on Workforce Productivity in an Iranian Petrochemical Industry. Saf Health Work, 8(1), 67-71.

Hom, P. W., Mitchell, T. R., Lee, T. W., \& Griffeth, R. W. (2012). Reviewing employee turnover: Focusing on proximal withdrawal States and an expanded criterion. Psychological Bulletin, 138(5), 831-858 https://doi.org/10.1037/a0027983

Huselid, M. A. (2018). The Impact Of Human Resource Management Practices On Turnover, Productivity, And Corporate Financial Performance. Academy of Management Journal, 38(3), 635-872 https://doi.org/10.5465/256741

Kalleberg, A. L. (1977). Work Values and Job Rewards: A Theory of Job Satisfaction. American Sociological Review 42(1), 124-143. https://doi.org/10.2307/2117735

Kuncoro, M. (2010). Metode Kuantitatif: Teori dan Aplikasi Untuk Bisnis dan Ekonomi. Yogyakarta : AMP YKPN

Hasibuan, M.A.P. (2012). Manajemen Sumber Daya Manusia. Jakarta: PT.Bumi Aksara. https://doi.org/10.1016/j.chemosphere.2018.05.062

Mathis R., L., \& Jackson J, H. (2004). Manajemen Sumber Daya Manusia Buku 1. Edisi Pertama, Penerbit Salemba Empat, Jakarta.

Mobley, W. H. (2011). Pergantian Karyawan: Sebab, Akibat dan Pengendaliannya (Terjemahan). Jakarta: PT Pustaka Binaman Pressindo.

Muayyad, D. M., \& Gawi, A. I. O. (2016). Pengaruh Kepuasan Kerja Terhadap Produktivitas Kerja Pegawai Bank Syariah X Kantor Wilayah II. Jurnal Manajemen Dan Pemasaran Jasa, 9(1), 75-98. https://doi.org/http://dx.doi.org/10.25105/jmpj.v9i1.1396

Robbins, P. S. (2002). Prinsip-Prinsip Perilaku Organisasi. (S. . Halida, S.E dan Dewi Sartika, Ed.) (5th ed.). Jakarta: Erlangga.

Robbins, S., \& Judge, T. A. (2013). Organizational Behavior 15th ed. Zhurnal Eksperimental'noi i Teoreticheskoi Fiziki. https://doi.org/10.12737/4477

Rompis, J., \& Sendow, G. (2019). Pengaruh Insentif, TurnOver dan Keterlibatan Kerja Terhadap Produktivitas Kerja Karyawan CV. Segarindo Utama Minahasa. EMBA : Jurnal Riset Ekonomi, Manajemen, Bisnis Dan Akuntansi, 7(1), 1081 - 1090. Retrieved from https://ejournal.unsrat.ac.id/index.php/emba/article/view/23239 
Saari, L. M., \& Judge, T. A. (2004). Employee attitudes and job satisfaction. Human Resource Management, 43(4), 395-407. https://doi.org/10.1002/hrm.20032

Said, M., Rumawas, W., \& Asaloei, S. I. (2017). Pengaruh Kepuasan Kerja Terhadap Produktivitas Kerja Karyawan Pada PT. Bank Mandiri (Persero) Tbk, Area Manado. Jurnal Administrasi Bisnis (JAB), 5(4) 1-9. Retrieved from https://ejournal.unsrat.ac.id/index.php/jab/issue/view/1780

Sauermann, J. (2016). Performance measures and worker productivity. IZA-World of Labor. Retrieved from https://wol.iza.org/uploads/articles/260/pdfs/performance-measures-andworker-productivity.pdf

Schwepker, C. H. (2001). Ethical climate's relationship to job satisfaction, organizational commitment, and turnover intention in the salesforce. Journal of Business Research, 54(1), 39-52. https://doi.org/10.1016/S0148-2963(00)00125-9

Sugiyono, P. D. (2013). Statistik untuk Penelitian. CV. Alvabeta Bandung. https://doi.org/10.1016/S0969-4765(04)00066-9

Wahyuni, A. S., Zaika, Y., \& Anwar, R. (2014). Analisis Faktor-Faktor Yang Mempengaruhi Turnover Intention (Keinginan Berpindah) Karyawan Pada Perusahan Jasa Konstruksi. Jurnal Rekayasa Sipil, 8(2), 89-95.

Yasa, I. W. M. (2017). Pengaruh Konflik Peran Dan Ambiguitas Peran Terhadap Kinerja Pegawai Melalui Mediasi Stres Kerja Pada Dinas Kesehatan Kota Denpasar Bali. Jurnal Ekonomi Dan Bisnis, 4(1), 38-57. https://doi.org/10.22225/JJ.4.1.203.38-57

Zaffane, R. (2003). Understanding Employee Turnover : The Need For a Contingency Approach. International Journal of Manpower 15(9/10). 22-37. 